\title{
CHEST INJURIES IN CHILDHOOD AND ADOLESCENCE
}

\author{
BY \\ B. J. BICKFORD \\ From the Regional Thoracic Surgical Centre, Broadgreen Hospital, Liverpool 14, and the Department of \\ Surgery, University of Liverpool
}

(RECEIVED FOR PUBLICATION FEBRUARY 26, 1962)

Serious injuries of the chest in the early years of life are relatively uncommon in clinical practice and appear to have received only scanty attention in the surgical literature. The present study was undertaken in order to obtain some facts about the incidence and nature of such injuries in Liverpool, and the results proved both interesting and surprising.

\section{The Material Studied}

A search was made through the case records of the Liverpool Thoracic Surgical Centre, which was established during World War II in 1940. Until the end of 1960 there had been 17,552 admissions, but only 423 were the result of trauma. Of these, 268 were admitted before the end of 1945 and were for the most part war injuries of various kinds, including the late results of battle casualties. There were thus 155 civilian injuries and, of these, taking 18 years of age as the arbitrary end of adolescence, 16 come within the terms of reference of this study. This is approximately $12 \%$ of the total cases of civilian thoracic trauma admitted to the centre. One of the children included in this series was, however, an air-raid casualty.

In order to make the picture more complete the records of Alder Hey Children's Hospital, Liverpool, were studied. This hospital is a busy general paediatric hospital with a casualty department to which a large number of children involved in accidents are taken. During the 10year period ending in 1960 there were about 90,000 admissions to the hospital including those due to accident. It was only possible, however, to discover 10 examples of chest injury. This term was used to include all patients in whom there was a major injury to the thoracic cage and its contained organs. Special care was taken to look at the records of cases of injury to the liver or spleen. There were 15 of these; all but two have been excluded from the present study because they were not associated with definite intrathoracic injury or fracture of the ribs.
Of the 26 cases thus included in the study it was a surprise to find that only three had simple rib fractures, while 11 had closed injuries with damage to the lung or air passages, and no fewer than ten had suffered from penetrating wounds.

It cannot be said with any degree of certainty, or indeed with any probability, that these cases represent the sum total of all the cases of thoracic injury to children and adolescents in the region; but they almost certainly comprise most of the cases of serious injury during the periods under review in this relatively compact urban area. There seems thus to be an a priori case for regarding the resultant picture of the type of chest injury suffered by these young people as being typical of their age group.

\section{CASE REPORTS}

Three types of chest injury were sustained by the 26 patients studied.

Simple Fractures of THE Ribs.-There were three cases in this group.

Case No. 1 (A.H.H. 13685).-A boy aged 14 months was knocked down by a lorry. He suffered from concussion and fractures of the third and fourth left ribs. He recovered.

Case No. 2 (A.H.H. 20957).-A boy of $6 \frac{1}{2}$ years was knocked down by a car. He sustained concussion and a fracture of the right second rib. He recovered.

Case No. 3 (A.H.H. 118863).-A boy of 7 years was knocked down by a car. He had a crack fracture of the occiput and fractures of the right sixth and eighth ribs. He recovered.

Closed Injury with Damage to Lung or Air Passages.-Thirteen cases were admitted.

Case No. 4 (B.G.H. 8264).-A boy of 7 years was riding on a potato-digging machine on a farm when the horses bolted. He was thrown into the air and a wheel of the machine ran over his chest. There was no fracture, but surgical emphysema and right clotted haemothorax developed. This could not be aspirated and later became infected, necessitating drainage of an empyema. He recovered.

Case No. 5 (B.G.H. 8711).-A boy of 16 years was run over by a lorry. He sustained a fracture of the 
left ninth rib with haemothorax and severe shock. At operation a spiral laceration of the left lower lobe was sutured. He recovered.

Case No. 6 (B.G.H. 13989).-A boy of 7 years was run over by a car. He suffered from concussion, subluxation of the right sterno-clavicular joint, and fractures of the seventh, eighth, and ninth ribs on the left side. A small haemothorax was aspirated. He recovered.

Case No. 7 (B.G.H. 14916).-A girl of 2 years was thrown against the windscreen of a car in which she was travelling when it crashed. She sustained fractures of the sixth, seventh, and eighth ribs on the right side with pneumothorax, cyanosis, and shock. At operation two lacerations of the right lower lobe were sutured. She recovered.

Case No. 8 (A.H.H. 10731). - A boy of 15 years was knocked down by a car. He suffered from a fractured right seventh rib and a small pneumothorax. He recovered.

Case No. 9 (A.H.H. 22948). - A boy of 22 months was knocked over by a slowly moving lorry. He sustained fractures of the sixth, seventh, and eighth ribs on the left and a haemothorax. He recovered.

Case No. 10 (A.H.H. 122260).-A boy of 12 was thrown 20 feet from a 15,000 volt electricity pylon. He suffered from electrical burns and paraplegia due to a fracture of the sixth thoracic vertebra and a laceration of the spinal cord. He also had extensive contusions of the lungs. Tracheostomy was performed, but he died five days after the accident.

Case No. 11 (B.G.H. 1811).-A boy of 12 years was crushed by a falling iron fence and pinned to the ground six years before. He was gravely ill and in hospital for nine months. A tracheostomy was performed. Collapse of the left lung was not diagnosed at that time. There was a stricture of the left main bronchus with total bronchiectasis beyond it. A left pneumonectomy was carried out. He recovered. This case has been reported by Sale (1954).

Case No. 12 (B.G.H. 4535).-A girl of 5 years had been run over by a horse-drawn cart five months previously. She had severe dyspnoea and haemoptysis at that time. She developed stenosis of the right "intermediate" bronchus with collapse but no infection of the right middle and lower lobes. A right middle and lower lobectomy was performed and she recovered.

Case No. 13 (A.H.H. 114571).-A girl of 5 years was knocked down by a lorry. She sustained multiple fractured ribs with bilateral pneumothorax. Cardiac arrest after intubation necessitated massage. A right lower lobectomy for rupture of the right lower lobe bronchus was performed, but she died of uncon trollable haemorrhage into the bronchial tree.

Case No. 14 (B.G.H. 10983).-A boy of 6 years was cornering too fast on a tricycle when he fell and struck his neck on the handlebars. He suffered from a left pneumothorax with surgical emphysema of the face and neck and over both clavicles. He recovered.

Case No. 15 (A.H.H. 6882). -A boy of $13 \frac{1}{2}$ years was admitted moribund after a road accident with multiple injuries including laceration of both lungs, ruptured spleen, fractures of the arm, clavicle, and skull, and subdural haemorrhage. He died.

Case No. 16 (A.H.H. 108972).-A boy of $7 \frac{1}{2}$ years was involved in a road traffic accident. He sustained a ruptured liver with haematoma of the lung. The liver was sutured and thoracotomy was not required. $\mathrm{He}$ recovered.

Penetrating Wounds.-Penetrating wounds were caused by the following:

(1) Missiles.-Two cases came into this group.

Case No. 17 (B.G.H. 52).-A boy of 17 years was injured by a bomb splinter in an air-raid. A haemopneumothorax was aspirated. A superficial wound was later explored because of infection. He recovered.

Case No. 18 (B.G.H. 5574).-A boy of 15 years was accidentally shot by a friend at a shootinggallery. A left haemopneumothorax was aspirated (total $1,450 \mathrm{ml}$.). A bullet was removed from beneath the skin of the back under local anaesthesia. $\mathrm{He}$ recovered.

(2) Spikes.-Seven patients sustained this type of injury.

Case No. 19 (A.H.H. 30209).-A boy of 12 years, a backward child at a special school, fell through a glass roof. He suffered from a penetrating wound through the left tenth intercostal space. The laceration of the lung was sutured, and he recovered.

Case No. 20 (B.G.H. 137).-A boy of 7 years fell from a telegraph pole on to a spike. The wound was explored, but the child did not recover consciousness after operation and died. Necropsy showed a contusion of the left atrium due to a penetrating injury. There was adherent clot on the subjacent endocardium, with embolization of the anterior and posterior cerebral arteries on the right side.

Case No. 21 (B.G.H. 212).-A boy of 10 years fell from a tree on to a spiked fence. He had a penetrating wound of the pleural cavity ; the chest radiograph was normal but there was some local surgical emphysema. The wound was explored and sutured. He recovered.

Case No. 22 (B.G.H. 8365).-A boy of 10 years was standing in a wedding crowd when he was pushed on to a spiked iron railing. A perforating wound of the left lower axillary region entered the pleural cavity but did not damage the lung. The wound was explored and sutured. He recovered.

Case No. 23 (B.G.H. 15897).-A girl of 15 years slipped and fell on to a spiked iron railing. She had a wound in the right axillary region $3 \mathrm{in}$. long and 
a small pneumothorax. The wound was excised and sutured. She recovered.

Case No. 24 (B.G.H. 15962).-While cycling, a boy of 17 years ran into a spiked fence. He had a puncture wound in the right side of the chest and local surgical emphysema but no pneumothorax. The wound was explored and sutured and he recovered.

Case No. 25 (B.G.H. 1558).-A boy of 18 years was knocked down by a car. A spike penetrated the right posterior axillary region, causing a haemopneumothorax. This was aspirated, and he was given a blood transfusion. The wound was excised. He recovered.

(3) Stab.-There was only one case of stab injury.

Case No. 26 (B.G.H. 2010).-A boy of 15 years was lying in bed, carving a piece of wood which he was balancing on the sternum. The knife slipped and he stabbed himself in the fifth left intercostal space $1 \mathrm{in}$. inside the nipple line. There was a small sucking wound and a haemopneumothorax. The chest was aspirated and the wound sutured. Two weeks later he was febrile and had fainting attacks in which he was hypotensive. A large pericardial effusion was aspirated (total $820 \mathrm{ml}$.). He recovered.

\section{COMMENT}

The present study revealed both that the number of children with chest injuries serious enough to demand admission to hospital in a large industrial area was small and that the actual injuries differed markedly from those of the adult pattern. Of the 155 cases of civilian chest injury admitted to the Liverpool Thoracic Surgical Centre during the period under review, 139 were adults and only nine had penetrating wounds. Of the 16 children and adolescents admitted to the centre, ten had penetrating wounds but one was a war casualty from an air-raid.

A study of the case records suggests that the high incidence of penetrating wounds in the children is due to the greater activity of these small persons as compared with adults. Apart from their curiosity and general enthusiasm for new experiences, children exhibit little caution in dangerous situations. Thus they climb trees, roofs, electricity pylons, and telephone poles, which adults seldom do except with due precaution; they ride bicycles with great speed and daring in narrow quarters and run into many and varied risks to which the more cautious and slow-moving adult is unwilling to expose himself. Belsey (1953) mentions the dramatic example of a small boy who had run into the back of a bus and whose chest had been impaled by the handlebar of his own bicycle. The boy's life had been saved by the presence of mind of a passer-by, who had plugged the sucking wound with the boy's own neck-tie. Such an incident is typical in its very quality of being unusual, as are many of the cases recorded above. Perhaps an incident similarly unique is that reported by Lagarde (1948). This Mexican journal is not available in this country, but the report concerns an infant in whom a pneumothorax had been produced by the father's caress.

There is little comment in the literature about the special aspects of chest injuries in childhood. There is, however, considerable evidence to confirm the opinion that chest injuries are relatively rare in children. Knoepp (1941) reported a series of 386 cases of fractures of the ribs and only eight of his patients were less than 20 years old. Similarly, Cameron, O'Rourke, and Burt (1949) reported on 109 patients with multiple rib fractures, only two of whom were under 20 years. The same authors (1950) reviewed a series of cases of perforating and penetrating wounds of the chest occurring in civilian practice in the United States. None of their patients was under the age of 10 , and only nine were under 20 years. Most of these wounds were, moreover, the result of criminal violence. Ninety-three were stabbings, 26 were gunshot wounds, and all but 18 were in men.

In Europe, Johansson and Silander (1959) reviewed 313 cases of thoracic injury occurring in Stockholm. Two hundred and ninety-three of these patients were suffering from rib fractures, but only seven were less than 20 years of age, and none was younger than 10 years. Apparently only four of the 20 patients without fractured ribs were children, the oldest being 13 years.

More akin to the present study is the report by Urech and Ramseyer (1959) on chest injuries among the young rural Vaudois in Switzerland. Fifteen patients between the ages of $2 \frac{1}{2}$ and 23 are described. Nine had been run over by farm carts or tractors, two had been thrown from moving vehicles, one had been knocked down by a car, one was in a car which overturned, one was kicked by a cow, and one young soldier fell from his horse and was trampled on by it. From these accidents the injuries were varied, but in only five cases were there demonstrable fractures of the ribs. In contrast to the series described in the present communication, there were no penetrating wounds. Two patients died soon after the accident, one primarily from extensive cerebral damage and one from an unrecognized laceration of the lung. One child of 9 died as the result of rupture of a false aneurysm of the aorta. This 
aneurysm arose above a coarctation of the aorta which did not appear to be of the usual congenital type, but was thought to have been the result of an injury when the child was run over by a cartwheel five or six years earlier.

It is worth noting that most childhood chest injuries seem to occur in boys, presumably on account of their greater physical activity and adventurous nature. In Urech and Ramseyer's cases 11 of the 15 were boys; in the series presented from Liverpool 21 of the 26 were boys.

In general it is reasonable to assume that the relative lack of serious fractures of the ribs in children is due to the elasticity of these bones during the early years of life. This enables the thoracic cage to withstand deforming stresses of remarkable severity without breaking, a fact on which Urech and Ramseyer also comment. The deforming stress may be enough to cause serious damage to internal thoracic viscera, such as the lung, the main air-passages or the aorta, without ribs being fractured. In the present series of 26 cases, only nine patients had demonstrable rib fractures. These were all caused by road vehicles, but only one was of the deceleration type common in adults. The common cause of this type of injury in a child is being knocked down by a vehicle while running across the road.

A very notable and perhaps unique feature of the present series is the high proportion of penetrating injuries. There were ten of these: two were due to missiles, seven to injury by spikes, and one to a stab. Apart from the one case due to a bomb splinter in an air-raid, all of these injuries were associated with the typical adventurousness, curiosity, and lack of caution exhibited by children. They afford an interesting insight into some of the hazards of young life, which are probably not sufficiently generally appreciated. There is no doubt that similar causes lead to most of the injuries that are suffered by children.

The management of these injuries presented in general no special difficulty except in case 13, who was admitted to hospital in extremis, and in whom haemorrhage into the bronchial tree was a major cause of respiratory embarrassment.

Apart from case 13, there were two patients in whom an early thoracotomy would have been helpful in treatment. Case 11 had a rupture of the left main bronchus leading to an unrecognized collapse of the left lung at a time when thoracic surgical facilities were not generally available. He did not come under observation again until six years after the accident when he had a stricture of the bronchus and total bronchiectasis in the lung distal to it. In case 12 there was collapse of the right middle and lower lobes distal to a stricture of the intermediate bronchus. The injury had occurred five months previously, and no doubt if the nature of the damage had been recognized earlier it would have been possible to resuture the bronchus and save the lobes supplied by it. It is evident that rupture of a bronchus must be considered when collapse of a lobe or a lung follows a thoracic injury.

The mortality in this series was four $(15 \%)$. Two of these patients were in extremis on admission (cases 13 and 15); another (case 10) died of multiple severe injuries including electrical burns and paraplegia. Contusion of the lungs was a contributory accelerating factor only. The fourth death was the bizarre result of a penetrating injury with cerebral embolism resulting from contusion of the left atrium and the rapid adherence of clot to the underlying endocardium (case 20).

\section{SUMMARY}

A series of 26 cases of thoracic injury occurring in children and adolescents under the age of 18 is described.

There were three examples of simple rib fractures, 13 closed injuries with damage to the lung or air-passages, and 10 penetrating wounds. The mortality was four (15\%).

The literature is reviewed, and the features of this type of injury are described.

I am grateful to my colleagues at the Thoracic Surgical Centre, Broadgreen Hospital, Liverpool, and to Miss Isabella Forshall and her surgical colleagues at Alder Hey Children's Hospital, Liverpool, for permission to give details of the cases treated by them.

\section{REFERENCES}

Belsey, R. (1953). Practitioner, 170, 134.

Cameron, D. A., O'Rourke, P. V., and Burt, C. W. (1949). Amer. S. Surg., 78, 668.

__ _ (1950). Ibid., 79, 361.

Johansson, L., and Silander, T. (1959). Acta chir.scand., Suppl. 245, 91.

Knoepp, L. F. (1941). Amer. J. Surg., 52, 405.

Lagarde, L. (1948). Acta med. hidalg., 1, 7.

Sale, T. A. (1954). $\quad$ Brit. J. Surg., 41, 625.

Urech, E., and Ramseyer, M. (1959). Schweir. med. Wschr., 89, 631. 